\title{
Synthesis of Silver Nanoparticles by Ocimum basilicum Seed Extract and its Application in $\mathrm{H}_{2} \mathrm{O}_{2}$ Sensing
}

\author{
Fouzia ${ }^{1}$, Atirah Tauseef ${ }^{2}$, Ahmad Khalilullah ${ }^{1}$ and Imran Uddin ${ }^{1 *}$ \\ ${ }^{1}$ Interdisciplinary Nanotechnology Centre, Zakir Husain College of Engineering and \\ Technology (ZHCET), Aligarh Muslim University, Aligarh, India \\ ${ }^{2}$ Department of Botany, Aligarh Muslim University, Aligarh, India \\ *Corresponding Author: Imran Uddin, Interdisciplinary Nanotechnology Centre, \\ Zakir Husain College of Engineering and Technology (ZHCET), Aligarh Muslim \\ University, Aligarh, India
}

\begin{abstract}
Plant extract mediated nanomaterials synthesis is one of the emanating fields of nanotechnology with voluminous applications in the physics, chemistry, biology, medicine, etc. Although different chemical techniques are on the brink of development, the rising concern for environmental contamination opens the path for biological synthesis as most of the chemical routes need toxic chemicals. The current piece of the study intended to synthesize silver nanoparticles by aqueous extract from the seed of the medicinal plant, Ocimum basilicum, under ambient conditions. A fixed ratio of plant extract to metal ion was prepared, and the color change was observed which proved the formation of nanoparticles. TEM analysis revealed silver nano-particles existed in a quasi-spherical shape with an average size of $11 \mathrm{~nm}$ in diameter. Moreover, the $\mathrm{H}_{2} \mathrm{O}_{2}$ sensing capacity of biologically synthesized AgNPs has also been studied.
\end{abstract}

Keywords: Ocimum basilicum; Silver Nanoparticles; Characterization; $\mathrm{H}_{2} \mathrm{O}_{2}$ Sensing

\section{Introduction}

The emergence of green nanotechnology is gaining interest these days due to their ecologically sound and cost-effective methods of synthesizing nano-materials. Metallic nanoparticles are attracting researchers attention due to their unique optical, electrical, and biological characteristics, making them suitable for various applications such as bio-sensing, imaging, optical spectroscopy, drug delivery, and catalysis [1]. Among the array of nanoparticles, silver nanoparticles (AgNPs) are believed to be full of promise in the nanotechnology industry and find a role in catalysis, material, energy and biomedicine [2-7]. These properties generally rely on the dimensions, shape, structure, and capping layer of nanoparticles $[8,9]$. The preferred route for the synthesis of AgNPs in the chemical reduction of ionic silver in the presence of reducing and stabilizing agents $[10,11]$. The environmental hazards associated with these chemicals paved the way for the green route of the synthesis of silver nanoparticles [12].

Moreover, the green route of synthesis is economical, devoid of deploying unsafe substances, high temperature, pressure and energy consuming processes that have detrimental effects in the medical field $[13,14]$. The deployment of plant extracts in nanoparticle synthesis is advantageous over microbes due to the ease of scale-up production, a small level of bio-hazard, and lack of need for complicated procedures in cell culture maintenance [15]. The deployment of plants and their parts in the synthesizing nanomaterial has been explored as a route of green synthesis of nanoparticles because extract derived from them possess different biomolecules including proteinaceous enzymes, phenolics, flavonoids, saponins, terpenoids, alkaloids which are responsible for reducing bulk or ionic form into nano-dimension of corresponding material [16]. Biomolecules such as flavonoids, proteins, and polysaccharides are responsible for the reduction of $\mathrm{Ag}^{+}$to $\mathrm{Ag}^{0}$ [17]. In the recent past, the extract of different plant species such as Eucalyptus chapmaniana, Arbutus unedo, Sesbania grandiflora, Allium sativum has been deployed in the synthesis of Ag Nps [1821]. Ocimum basilicum seeds are sources of a wide range of secondary metabolites such as phenolics and polyphenols, including flavonoids and anthocyanins [22]. These seeds are the plentiful insoluble fiber that maintains gut health, cholesterol level, blood sugar, and appetite. Ocimum basilicum seeds are rich in flavonoids which have antioxidant, anti-bacterial, anti-inflammatory and anticancerous properties. The Presence of these biomolecules makes these seeds an excellent candidate in the synthesis of nanoparticles. The remarkable characteristics of AgNPs such as small size, 
larger surface-area-to-volume ratio, and spherical shape, facilitate attachment with the microbial cell wall, thereby imparting more significant antimicrobial effects [23].

Hydrogen peroxide $\left(\mathrm{H}_{2} \mathrm{O}_{2}\right)$ a strong oxidant that finds potent applications in food, cosmetics, wood pulp, and pharmaceutical industries. Despite relevance, its presence in trace amounts may be accounted for the numerous health and environmental hazards due to toxicity. Thus, there is a need for designing a competent colorimetric sensor that can rapidly detect $\mathrm{H}_{2} \mathrm{O}_{2}$ in various samples [24]. Moreover, Selvaraj and co-workers also reported the sensing capacity of AgNps synthesized by deploying E.coli [25]. The capability of AgNPs in reducing hydrogen peroxide resulting in their decolorization has been investigated for the fabrication of simple and cost-effective colorimetric $\mathrm{H}_{2} \mathrm{O}_{2}$ sensor which can swiftly sense hydrogen peroxide.

\section{Materials and Methods}

Silver nitrate $\left(\mathrm{AgNO}_{3}\right)$ was purchased from Rankem fine chemical laboratory Ltd (RFCL). Ethanol was purchased from Merck (Germany). All glassware is of Borosil company. Ocimum basilicum seed was brought from Ajmal Khan Tibbiya Collage AMU, Aligarh. All reagents, used in the synthesis work, were of analytical grade and were purchased from commercial sources and utilized without further purification. Firstly, we take $80 \mathrm{ml}$ distilled water and $20 \mathrm{ml}$ ethanol in a conical flask. A certain weight of Ocimum basilicum seeds (5gm) was boiled in $100 \mathrm{ml}$ solution (water + ethanol) for 30 minutes to obtain the seeds extract through filter paper. The filtered extract was used as a reducing agent. This boiled extract was refrigerated and used for the experimental procedure.

$1 \mathrm{mM}$ solution of silver nitrate $\left(\mathrm{AgNO}_{3}\right)$ from stock solution was prepared using sterile deionized double distilled water. $1 \mathrm{ml}$ of $\mathrm{Oci}^{-}$ mum basilicum seed extract was added to $5 \mathrm{ml}$ of $\left(1 \times 10^{-3} \mathrm{M}\right)$ aqueous silver nitrate $\left(\mathrm{AgNO}_{3}\right)$ solution, and the reaction was left to take place at ambient conditions. The observed change in color from transparent to light yellow brown color indicating that the formation of Ag Nps. The as-prepared solution was then used to inspect the formation of nanoparticles by UV-Vis spectroscopy, Transmission electron microscopy (TEM), X-ray diffraction (XRD) analysis and Fourier transform infrared (FTIR) spectroscopy. The optical property of AgNPs was determined by the Cary series UV-VIS-NIR spectrophotometer system (Aligent Technologies) was operated at a resolution of $1 \mathrm{~nm}$ in the wavelength range of 200-800 nm. To find out the morphology of Ag Nps, measurements were performed on the JEOL JEM 2100F transmission electron microscope
(TEM) operated at an accelerating voltage of $200 \mathrm{KV}$ at university Sophisticated Instrument Facility, AMU. The samples T.E.M were prepared by drop coating on to a carbon copper grid. To confirm the crystallinity of synthesized Ag Nps, XRD data were recorded using RigakuMiniflex-II X-ray diffractometer equipped with highintensity $\mathrm{Cu}-\mathrm{K} \alpha$ radiations $\left(\lambda=1.5406 \mathrm{~A}^{\circ}\right.$ ) operated at a voltage of $30 \mathrm{kV}$ and a current of $15 \mathrm{~mA}$ at the scan rate of $2^{\circ} / \mathrm{min}$ in the $2 \theta$ range of $30-80^{\circ}$. The chemical constituents in the bio-synthesized silver nanoparticles was studied by using FTIR spectroscopy measurement on the sample using a $\mathrm{KBr}$ pellet was performed by using a Perkin-Elmer Spectrum One instrument. The spectrometer was operated in the diffuse reflectance mode at a resolution of $2 \mathrm{~cm}^{-1}$. To obtain good signal to noise ratio, 128 scans of the powder were taken in the range of $450-4000 \mathrm{~cm}^{-1}$. The colorimetric detection of $\mathrm{H}_{2} \mathrm{O}_{2}$ via $\mathrm{Ag}$ Nps was done by adding $1 \mathrm{ml} \mathrm{H}_{2} \mathrm{O}_{2}$ in $3 \mathrm{ml} \mathrm{Ag} \mathrm{Nps}$ in a test tube. The resulting solutions were monitored by UV-Visible spectroscopy analysis at different time intervals.

\section{Results and Discussion}

Silver nanoparticles synthesized by using Ocimum basilicum seeds extract was characterized by UV-Vis absorption spectra. In figure 1, curve 1 shows a single peak maximum of seeds extracts at $243 \mathrm{~nm}$, which comes due to the presence aromatic compound present in the seed extract. In curve 2, which displayed peaks at $243 \mathrm{~nm}$ (due to seed extract) and absorption at 421 which is characteristic absorption of Ag NPs [26] The emergence of a sharp absorption peak at $421 \mathrm{~nm}$ indicates the formation of silver nanoparticles.

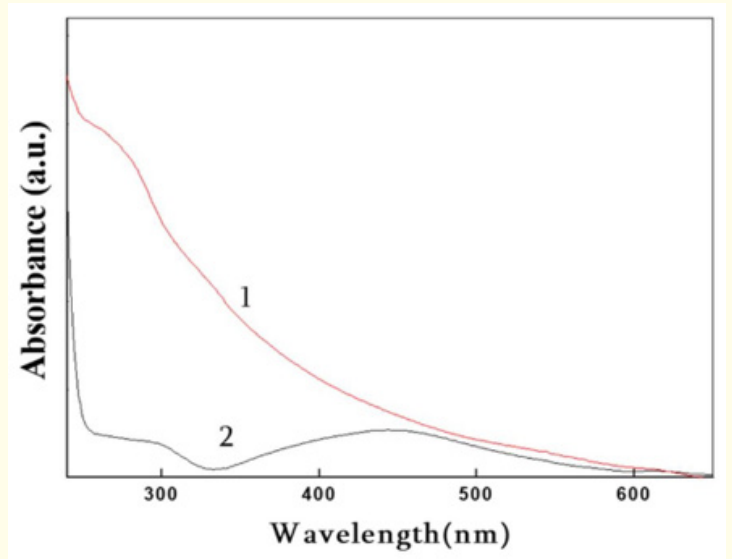

Figure 1: UV-Visible spectra (1) Ocimum basilicum seed extract (2) Ag Nps after reaction with plant seeds extract of the reaction mixture. 
In figure 2a, a TEM micrograph of as-synthesized Ag nanoparticles is shown, which revealed that the nanoparticles are quasispherical in shape and capped with the seed extract. The obtained silver nanoparticles are free from aggregation. The particle size of Ag Nps is in range of 6-15 nm, in which most of the Nps are of 11 $\mathrm{nm}$ in size (Figure 2b). These Nps are relatively stable even after prolonged storage [27].

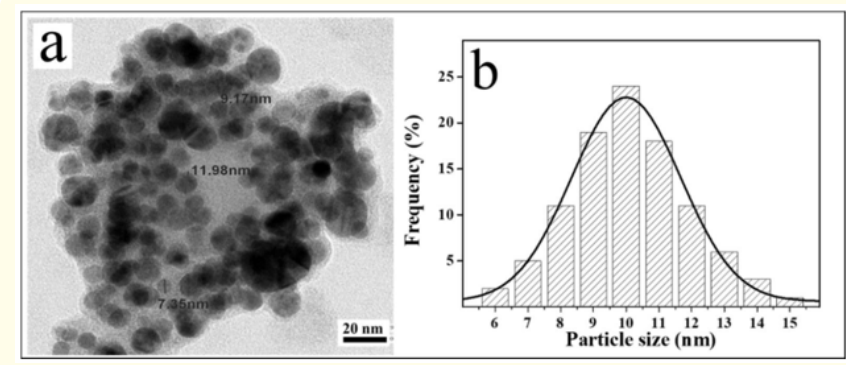

Figure 2: (a) TEM images of Ag nanoparticles obtained after reaction between seeds extract and $\mathrm{AgNO}_{3}$

(b) Particle size histogram.

XRD analysis reveals the crystalline nature of Ag NPs. The diffracted intensities were recorded from $30^{\circ}$ to $80^{\circ}(2 \theta)$, XRD peaks were observed corresponding to reflection planes (111), (200), (220), (311) at $38.52^{\circ}, 43.23^{\circ}, 64.84^{\circ}$ and $77.32^{\circ}$ of metallic silver nanoparticles [28]. All the peaks are well-matched with the standard JCPDS file No 040783.

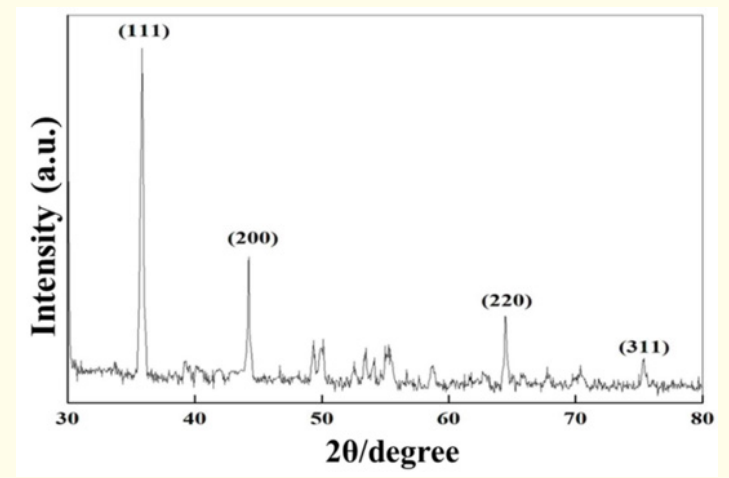

Figure 3: Powder XRD pattern of drop cast film of Ag nanoparticles on glass substrate after reaction with the herbal extract of Ocimum basilicum seeds extract.

FTIR measurements were accomplished to identify the presence of various functional groups in biomolecules responsible for the bioreduction of $\mathrm{Ag}^{+}$and capping/stabilization of silver nanoparticles. FTIR spectrum of synthesized Ag NPs was shown in figure 4. The band at $3472 \mathrm{~cm}^{-1}$ in the spectrum corresponds to $\mathrm{O}-\mathrm{H}$ stretching vibration indicating the presence of alcohol and phenol. The band at $2912 \mathrm{~cm}^{-1}$ and $2867 \mathrm{~cm}^{-1}$ region arising from C-H stretching of the aromatic compound were observed. The band at $1768 \mathrm{~cm}$ ${ }^{1}$ was assigned for (C-C) stretching (non-conjugated). The band at $1642 \mathrm{~cm}^{-1}$ in the spectra corresponds to $\mathrm{C}-\mathrm{N}$ and C-C stretching, indicating the presence of protein [29]. The band at $1450 \mathrm{~cm}^{-1}$ was assigned for $\mathrm{N}-\mathrm{H}$ stretch vibration present in the amide linkage of the proteins. These functional groups have a role in the stability/capping of Ag NPs [30]. The band at 1450 and $1062 \mathrm{~cm}^{-1}$ were assigned for $\mathrm{N}-\mathrm{H}$ and $\mathrm{C}-\mathrm{N}$ (amines) stretch vibrations of the proteins, respectively. FTIR spectrum of Ocimum basilicum seed aqueous extract was shown in figure 4 . The band at $3429 \mathrm{~cm}^{-1}, 2931 \mathrm{~cm}^{-1}, 2861 \mathrm{~cm}^{-1}$, $1631 \mathrm{~cm}^{-1}, 1436 \mathrm{~cm}^{-1}, 1342 \mathrm{~cm}^{-1}, 1124-911 \mathrm{~cm}^{-1}$ corresponds to polyphenols, carboxylic acids its derivative $(\mathrm{C}=0), \mathrm{N}-\mathrm{H}$ stretching and $\mathrm{C}=\mathrm{N}$ stretching of aliphatic amines of seed extracts.

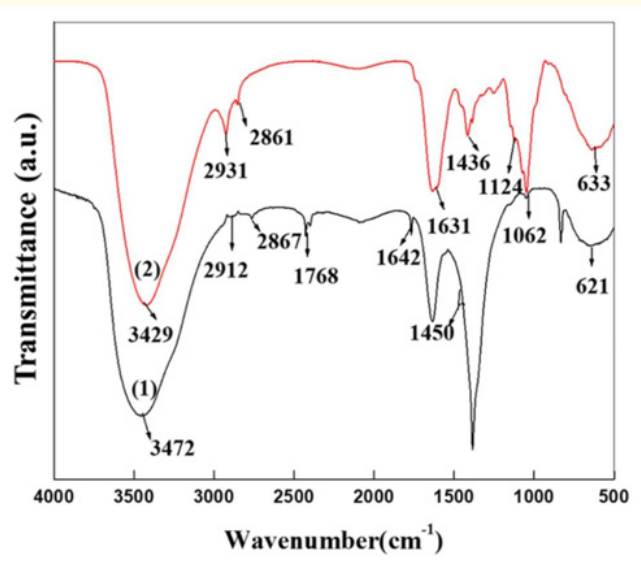

Figure 4: FTIR spectra recorded from as-synthesized Ag nanoparticles (curve 1) and seeds extract (curve 2).

The hydrogen peroxide $\left(\mathrm{H}_{2} \mathrm{O}_{2}\right)$ sensing was studied on the reaction of Ag NPs with $\mathrm{H}_{2} \mathrm{O}_{2}$, which lead to the change of the color of the solution containing Ag Nps from yellowish to colorless. The presence of Ag NPs in the solution results in an influential absorption band at $421 \mathrm{~nm}$. The UV-Vis spectra of samples containing $\mathrm{H}_{2} \mathrm{O}_{2}$ concentrations are shown in figure 5. Ag NPs can detect the presence of hydrogen peroxide $\mathrm{H}_{2} \mathrm{O}_{2}$ in a sample was affirmed by adding $1 \mathrm{ml}$ of $20 \mathrm{mM} \mathrm{H}_{2} \mathrm{O}_{2}$ to $3 \mathrm{ml} \mathrm{Ag} \mathrm{NPs} \mathrm{solution.} \mathrm{The} \mathrm{UV-Vis}$ spectrum was recorded as a function of time at regular intervals. The decreasing trend in the absorbance peak of Ag NPs with the time increased, and eventually the characteristic peak of silver 
nanoparticles at $421 \mathrm{~nm}$ disappeared [31]. This corroborated silver nanoparticles nanoparticles' ability to decompose hydrogen peroxide and thus provide a means of detecting its composition. Therefore, Ag NPs in hybrid will be etched from $\mathrm{Ag}^{0}$ to $\mathrm{Ag}^{+}$. So, the concentration of $\mathrm{Ag}^{0}$ will decrease, leading to the fading of the $\mathrm{Ag}$ NPs solution and then to colorless after adding $\mathrm{H}_{2} \mathrm{O}_{2}$. The above behavior provides a potential for quantitative detection of $\mathrm{H}_{2} \mathrm{O}_{2}$ by measuring the Ag NPs surface plasmon resonance reduction at 421 $\mathrm{nm}$. The correlation between the concentration of hydrogen peroxide and a decrease in the absorbance of silver nanoparticles as a function of time could be used as a measure to detect the $\mathrm{H}_{2} \mathrm{O}_{2}$ in unknown samples rapid.

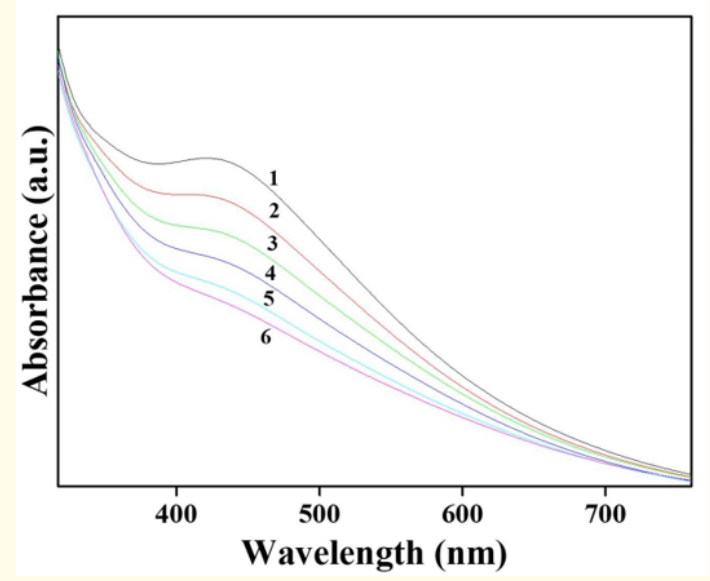

Figure 4: UV-Visible absorption spectrum of biosynthesized Ag Nps after adding $\mathrm{H} 2 \mathrm{O} 2$ at different intervals of time; 0 minute (curve 1), 1 minute (curve 2), 2 minutes (curve 3), 3 minutes (curve 4), 5 minutes (curve 5), 10 minutes (curve 6).

\section{Conclusion}

In conclusion, we developed a simple green protocol for the synthesis of noble metal nanoparticles (Silver) from Ocimum basilicum plant seed aqueous extract. Synthesis of Ag Nps was studied through different characterization techniques. The primary confirmation of color changes from light colorless to yellowish-brown color was observed at $421 \mathrm{~nm}$ and recorded by UV-Vis spectroscopy. FTIR results proved that bioactive compounds from Ocimum basilicum plant seed aqueous extract are responsible for silver bioreduction. The Ag Nps formed were in the average size range of $11 \mathrm{~nm}$ with zspherical morphology. X-ray diffraction pattern corroborated the crystalline nature of Ag Nps. The sensing capacity of $\mathrm{Ag} \mathrm{N}$ s towards $\mathrm{H}_{2} \mathrm{O}_{2}$ was also demonstrated. Hence the Ag Nps formed by this green synthesis method can be used as a probe for the detection of hydrogen peroxide in different samples.

\section{Acknowledgments}

The authors are thankful to the University's sophisticated instrumentation facility (USIF) and Interdisciplinary Nanotechnology Center (INC) for imparting necessary facilities to conduct this research.

\section{Bibliography}

1. Baghayeri M and Veisi H. "Fabrication of a facile electrochemical biosensor for hydrogen peroxide using efficient catalysis of hemoglobin on the porous $\mathrm{Pd} @ \mathrm{Fe}_{3} \mathrm{O}_{4}$-MWCNT nanocomposite". Biosensors and Bioelectronics Journal 74 (2015):190-198.

2. Imran Uddin., et al. "Bio-inspired synthesis of nanoherbal cream and its antimicrobial effect". Current Nanomedicine 8 (2018): 160-168.

3. Krishnakumar B., et al. "AgBr-ZnO-an efficient nano-photocatalyst for the mineralization of Acid Black 1 with UV light". Separation and Purification Technology 85 (2012): 35-44.

4. Subash B., et al. " $\beta-\mathrm{Ag}_{2} \mathrm{~S}-\mathrm{ZnO}$ as a novel sunshine photocatalyst for the effective degradation of RR 120 dye". Powder Technology 241 (2013): 49-59.

5. Ojodomo J Achadu., et al. "The interaction between graphene quantum dots grafted with polyethyleneimine and Au@Ag nanoparticles: Application as a fluorescence "turn-on" nanoprobe". Journal of Photochemistry and Photobiology A: Chemistry 324 (2016) 96-105.

6. Irudhaya Raj., et al. "Ultrasmall Sub-10 nm Aqueous Starch Capped CuS Quantum Dots with Tunable Localized Surface Plasmon Resonance and Composition for Selective and Sensitive Detection of Mercury (II) Ions". RSC Advances 10 (2020) 14050-14059.

7. Baghayeri M., et al. "Ag nanoparticles decorated $\mathrm{Fe}_{3} \mathrm{O}_{4}$ /chitosan nanocomposite: synthesis, characterization, and application toward electrochemical sensing of hydrogen peroxide". Journal of the Iranian Chemical Society 15 (2018): 1015-1022.

8. Ivask A., et al. "Size-dependent toxicity of silver nanoparticles to bacteria, yeast, algae, crustaceans and mammalian cells in vitro". Plos One 9 (2014): 1-14. 
9. Bastus NG., et al. "Synthesis of highly monodisperse citratestabilized silver nanoparticles of up to $200 \mathrm{~nm}$ : kinetic control and catalytic properties". Chemistry of Material 26 (2014): 2836-2846.

10. Imran Uddin. "Mechanistic approach to study conjugation of nanoparticles for biomedical applications". Spectrochimica Acta Part A: Molecular and Biomolecular Spectroscopy 202 (2018) 238-243.

11. Banerjee S., et al. "Structural evolution of silver nanoparticles during wet-chemical synthesis". Chemistry of Material 26 (2014): 951-957.

12. Ibrahim HMM. "Green synthesis and characterization of silver nanoparticles using banana peel extract and their antimicrobial activity against representative microorganisms". Journal Radiation Research and Applied Science 8 (2015): 265-275.

13. Sharma VK., et al. "Silver nanoparticles: green synthesis and their antimicrobial activities". Advances in Colloid Interface Science 145 (2009): 83-96.

14. Guo G., et al. "Preparation and dispersive mechanism of highly dispersive ultrafine silver powder". Applied Surface Science 256 (2010): 6683-6687.

15. Kalishwaralal K., et al. "Biosynthesis of silver and gold nanoparticles using Brevibacterium casei". Colloids and Surfaces B: Biointerfaces 77 (2010): 257-262.

16. Tavakoli F., et al. "Green synthesis of flower-like CuI microstructures composed of trigonal nanostructures using pomegranate juice". Material Letters 100 (2013): 133-136.

17. Speth TF and Varma RS. "Microwave-assisted green synthesis of silver nanostructures". Accounts of Chemical Research 44 (2011): 469-478.

18. Sulaiman GM., et al. "Green synthesis, antimicrobial and cytotoxic effects of silver nanoparticles using Eucalyptus chapmaniana leaves extract". Asian Pacific Journal of Tropical Biomedicine 3 (2013): 58-63.

19. Kouvaris P., et al. "Green synthesis and characterization of silver nanoparticles produced using Arbutus Unedo leaf extract". Material Letters 76 (2012): 18-20.
20. Das J., et al. "Sesbania grandiflora leaf extract mediated green synthesis of antibacterial silver nanoparticles against selected human pathogens". Spectrochimica Acta, Part A: Molecular and Biomolecular Spectroscopy 104 (2013): 265-270.

21. Ahamed M., et al. "Green synthesis, characterization and evaluation of biocompatibility of silver nanoparticles". Physica E: Low-dimensional Systems and Nanostructures 43 (2011): 1266-1271.

22. WB Phippen and JE Simon. "Anthocyanins in basil (Ocimum basilicum L.)". Journal of Agricultural and Food Chemistry 46 (1998): 1734-1738.

23. Agnihotri S., et al. "Size-controlled Silver Nanoparticles Synthesized over the Range 5-100 nm Using the Same Protocol and their Antibacterial Efficacy". RSC Advances 4 (2014): 3974-3983.

24. Chen W., et al. "Recent advances in electrochemical sensing for hydrogen peroxide: a review”. Analyst 137 (2012): 49-58.

25. Selvaraj R., et al. "Green biosynthesis of silver nanoparticles using Calliandra haematocephala leaf extract, their antibacterial activity and hydrogen peroxide sensing capability". Arabian Journal of Chemistry 10 (2017): 253-261.

26. Priyabrata M., et al. "Fungus-Mediated Synthesis of Silver Nanoparticles and Their Immobilization in the Mycelial Matrix: A Novel Biological Approach to Nanoparticle Synthesis". Nano Letters 1 (2001): 515-519.

27. Imran Uddin., et al. "Synthesis of silver nanoparticles using Matricaria recutita (Babunah) plant extract and its study as mercury ions sensor". Sensing and Bio-Sensing Research 16 (2017) 62-67.

28. Prema P and Raju R. "Fabrication and Characterization of Silver Nanoparticle and its Potential Antibacterial Activity". Biotechnology and Bioprocess Engineering 14 (2009): 842-847.

29. Prakasha P., et al. "Green synthesis of silver nanoparticles from leaf extract of Mimusops elengi, Linn. for enhanced antibacterial activity against multidrug-resistant clinical isolates". Colloids and Surfaces B: Biointerfaces 108 (2013): 255-259.

30. Niraimathi KL. "Biosynthesis of silver nanoparticles using Alternanthera sessilis (Linn.) extract and their antimicrobial, antioxidant activities". Colloids and Surfaces B: Biointerfaces 102 (2013): 288-291. 
31. Zhang L and Lia L. "Colorimetric detection of hydrogen peroxide using silver nanoparticles with three different morphologies". Analytical Methods 8 (2016): 6691-6695.

\section{Assets from publication with us}

- Prompt Acknowledgement after receiving the article

- Thorough Double blinded peer review

- Rapid Publication

- Issue of Publication Certificate

- High visibility of your Published work

Website: https://www.actascientific.com/

Submit Article: https://www.actascientific.com/submission.php Email us: editor@actascientific.com

Contact us: +919182824667 